\title{
In vitro migration capacity of human adipose tissue-derived mesenchymal stem cells reflects their expression of receptors for chemokines and growth factors
}

\author{
Sun Jin Baek, Sung Keun Kang \\ and Jeong Chan $\mathrm{Ra}^{1}$ \\ Stem Cell Research Center \\ RNL BIO Co., Ltd. \\ Seoul 153-768, Korea \\ ${ }^{1}$ Correspondence: Tel, 82-2-858-8021; \\ Fax, 82-2-858-8140; E-mail, jcra@rnl.co.kr \\ http://dx.doi.org/10.3858/emm.2011.43.10.069
}

Accepted 4 August 2011

Available Online 17 August 2011

Abbreviations: AdMSC, adipose tissue-derived mesenchymal stem cell; BCA-1, B-cell attracting chemokine-1; bFGF, basic fibroblast growth factor; BMMSC, bone marrow-derived mesenchymal stem cell; CCR, C-C chemokine receptor type; CXCL16, C-X-C motif chemokine 16; CXCR, C-X-C chemokine receptor type; FGFR1, fibroblast growth factor receptor 1; GF, growth factor; hAdMSC, human adipose tissue-derived mesenchymal stem cell; HGF, hepatocyte growth factor; IGF-1, insulin-like growth factor-1; IGF1R, insulin-like growth factor-1 receptor; MCP, monocyte chemotactic protein; MIP, macrophage inflammatory protein; MSC, mesenchymal stem cell; MT1-MMP, membrane type 1-matrix metalloproteinase; PBMC, peripheral blood mononuclear cell; PDGFRA, PDGF receptor A; PDGFRB, PDGF receptor B; SDF-1 $\alpha$, stromal-derived factor-1 $\alpha$; TGFBR2, TGF- $\beta$ receptor 2 ; TNFRSF1A, TNF receptor superfamily, member $1 \mathrm{~A}$

\begin{abstract}
The homing properties of adipose tissue-derived mesenchymal stem cells (AdMSCs) have stimulated intravenous applications for their use in stem cell therapy. However, the soluble factors and corresponding cellular receptors responsible for inducing chemotaxis of AdMSCs have not yet been reported. In the present study, the migration capacity of human AdMSCs (hAdMSCs) toward various cytokines or growth factors (GFs) and the expression of their receptors were determined. In a conventional migration assay, PDGF-AB, TGF- $\beta 1$, and TNF- $\alpha$ showed the most effective chemoattractant activity. When AdMSCs were preincubated with various chemokines or GF, and then allowed to migrate toward medium containing $10 \%$ FBS, those preincubated with TNF- $\alpha$ showed the highest
\end{abstract}

migratory activity. Next, hAdMSCs were either preincubated or not with TNF- $\alpha$, and allowed to migrate in response to various GFs or chemokines. Prestimulation with TNF- $\alpha$ increased the migration activity of hAdMSC s compared to unstimulated hAdMSCs. When analyzed by FACS and RT-PCR methods, hAdMSCs were found to express $\mathrm{C}-\mathrm{C}$ chemokine receptor type 1 (CCR1), CCR7, C-X-C chemokine receptor type 4 (CXCR4), CXCR5, CXCR6, EGF receptor, fibroblast growth factor receptor 1 , TGF- $\beta$ receptor 2 , TNF receptor superfamily member $1 A, P D G F$ receptor $A$ and PDGF receptor $B$ at both the protein and the mRNA levels. These results indicate that the migration capacity of hAdMSCs is controlled by various GFs and chemokines. Prior in vitro modulation of the homing capacity of hAdMSCs could stimulate their movement into injured sites in vivo when administered intravenously, thereby improving their therapeutic potential.

Keywords: adipose tissue; cell migration assays; cell movement; chemokines; cytokines; mesenchymal stem cells; receptors, chemokine; receptors, cytokine

\section{Introduction}

Adult mesenschymal stem cells (MSCs) have an inherent capacity to self-renew and to differentiate, making them very attractive for use in cell therapy and regenerative medicine. MSCs are found in various tissues, including bone marrow (Pittenger et al., 1999), umbilical cord blood (Erices et al., 2000), placenta (in 't Anker et al., 2004) and fats (Zuk et al., 2001). In particular, adipose tissue-derived MSCs (AdMSCs) have recently received attention as a promising source of cells for stem cell therapy. AdMSCs can be easily harvested from patients by a simple, minimally invasive method and are more abundant than bone marrow-derived mesenchymal stem cells (BMMSCs). Adipose tissues contain hundreds of thousands of MSCs in each gram of fat (Sen et al., 2001), while BMMSCs in the bone marrow fraction constitute a mere $0.0001-0.01 \%$ of all nucleated cells (Pittenger et al., 1999). Similar to BMMSCs, the efficacy of AdMSCs in treating various diseases has been reported using animal models 
(Mizuno, 2010). Local or systemic administration of AdMSCs was reported to induce repair of myocardial infarction (Cai et al., 2009), liver injury (Banas et al., 2008), hypoxia-ischemia-induced brain damage (Wei et al., 2009), allergic rhinitis (Cho et al., 2009) and muscular dystrophy (Bacou et al., 2004).

One of the more interesting characteristics of MSCs is their ability to migrate to areas of tissue injury. MSCs delivered intravenously following myocardial infarction were localized to the infarct region and improved ventricular function (Saito et al., 2002). Furthermore, localized abdomen irradiation significantly enhanced the homing of BMMSCs to radiation-injured tissues of mice (Mouiseddine et al., 2007). Numerous in vitro and in vivo studies have shown that chemokines or growth factors (GFs) are involved in the trafficking of BMMSCs to the injury region. The evidence suggests that interactions of stromal cell-derived factor- $1 \alpha$ (SDF-1 $\alpha$ ) and $\mathrm{C}-\mathrm{X}-\mathrm{C}$ chemokine receptor type 4 (CXCR4) mediated the trafficking of transplanted BMMSCs in a rat model of left hypoglossal nerve injury. In addition, BMMSCs were attracted by chemokines that are presented in the supernatants of primary cultures of human pancreatic islets both in vitro and in vivo (Sordi et al., 2005).

A recent study demonstrated the homing properties of intravenously administered AdMSCs to cell-damaged areas in an allergic rhinitis animal model (Cho et al., 2009). However, the soluble factors and receptors that are responsible for inducing chemotaxis of AdMSCs have not yet been identified. Accordingly, the present study investigated the in vitro migration ability of human AdMSCs (hAdMSCs) in response to a panel of chemokines and GFs, as well as their expression of receptors for chemokines and GFs.

\section{Results}

\section{Chemokines and GFs induce migration of AdMSCs}

To confirm that chemokines and GFs can regulate the migration of hAdMSCs, the chemotaxis of hAdMSCs toward chemokines and GFs was tested using an in vitro cell migration assay. As shown in Figure $1 \mathrm{~A}$, the GFs used in this study were better chemoattractants than the chemokines, and all of the GFs employed exhibited the ability to attract hAdMSCs. The highest chemotactic activity was observed with PDGF-AB ( 10.3-fold when compared with unstimulated control cells), TGF- $\beta 1$ ( 7.3 -fold) and TNF- $\alpha$ ( $\sim 6.6$-fold). While the chemokines employed were also able to induce migratory activity, the corresponding values for the chemokines did

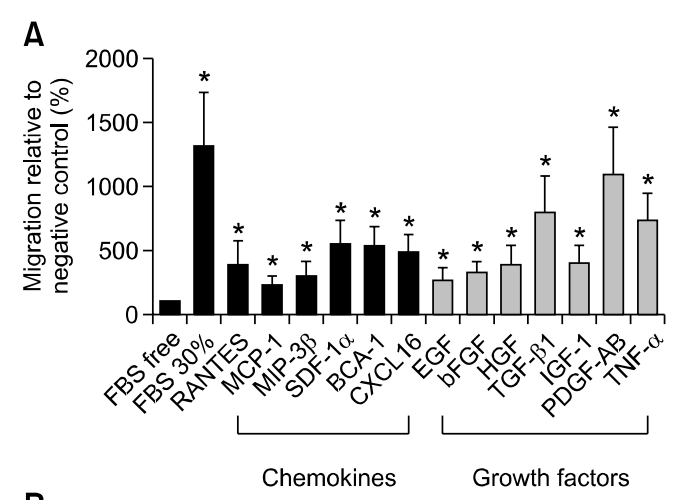

B
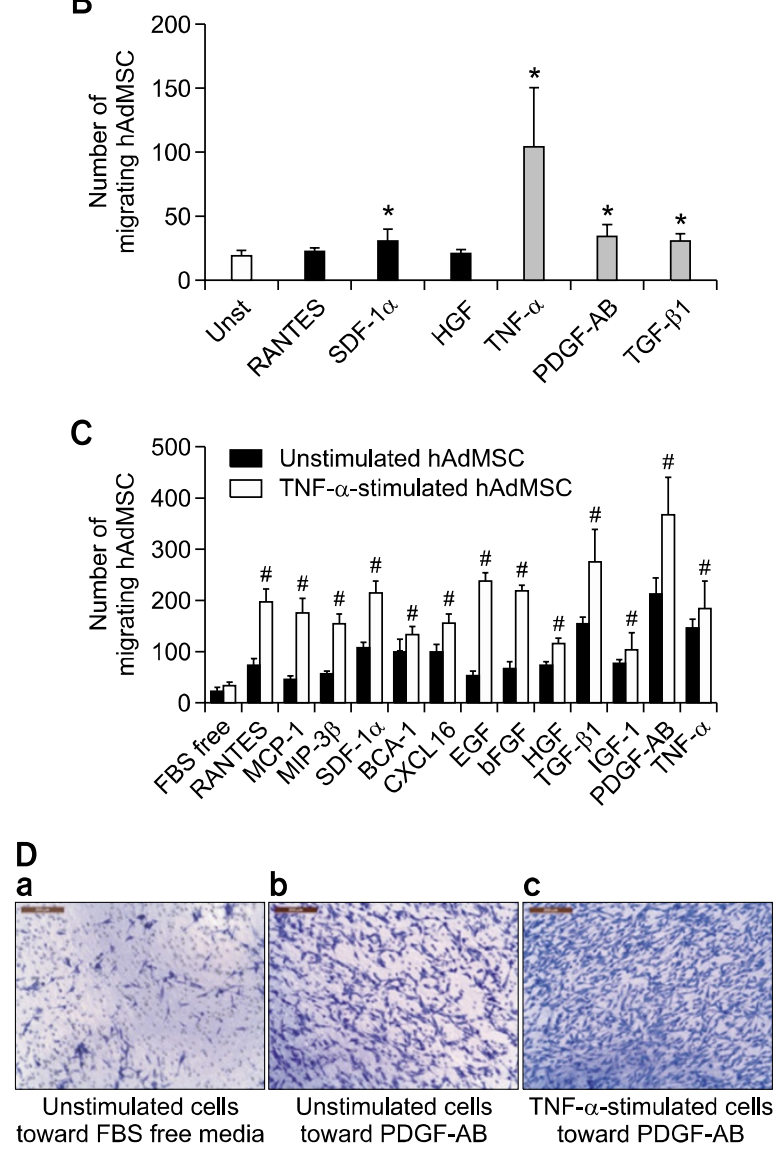

Figure 1. Migratory capacity of human adipose tissue-derived mesenchymal stem cells (hAdMSCs) toward chemokines and growth factors (GFs) in vitro. (A) Migration of unstimulated hAdMSCs. The hAdMSCs were plated and allowed to migrate toward medium containing chemokines or GFs $(100 \mathrm{ng} / \mathrm{ml})$. (B) Migration of hAdMSCs prestimulated with a GF or chemokine. The hAdMSCs were prestimulated with RANTES, SDF- $1 \alpha$, HGF, TNF- $\alpha$, PDGF-AB or TGF- $\beta 1$ (100 ng/ml for $24 \mathrm{~h}$ ) and allowed to migrate toward medium containing $10 \%$ FBS. (C) Migration of hAdMSCs prestimulated with TNF- $\alpha$. The hAdMSCs were prestimulated with TNF- $\alpha(100 \mathrm{ng} / \mathrm{ml}$ for $24 \mathrm{~h})$ and were allowed to migrate toward medium containing each chemokine or GF $(100 \mathrm{ng} / \mathrm{ml})$. (D) Representative crystal violet stained cells. Images show unstimulated hAdMSCs migrating toward FBS free medium alone (a) or PDGF-AB (b) and TNF- $\alpha$ prestimulated hAdMSCs migrating toward PDGF-AB (c). Columns represent the mean percentage of migrating cells relative to the negative control, and bars represent the SD from three independent experiments. FBS-free and $30 \%$ FBS-containing medium were used as the negative and positive control, respectively. ${ }^{*}, P<0.05$. Scale bar $=200 \mu \mathrm{m}$. 
A
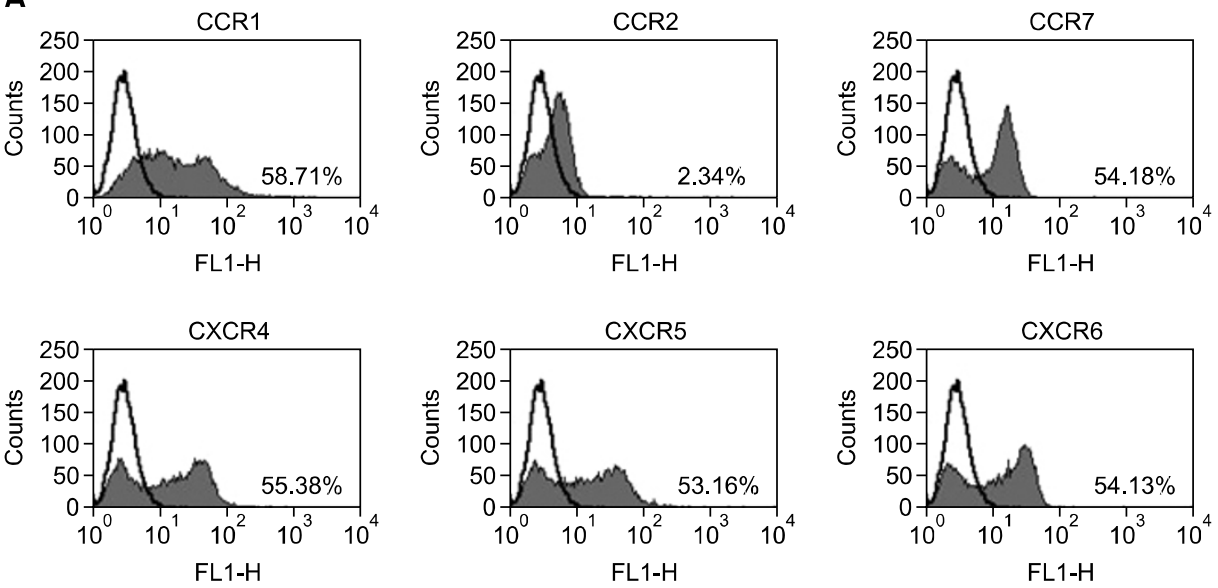

B
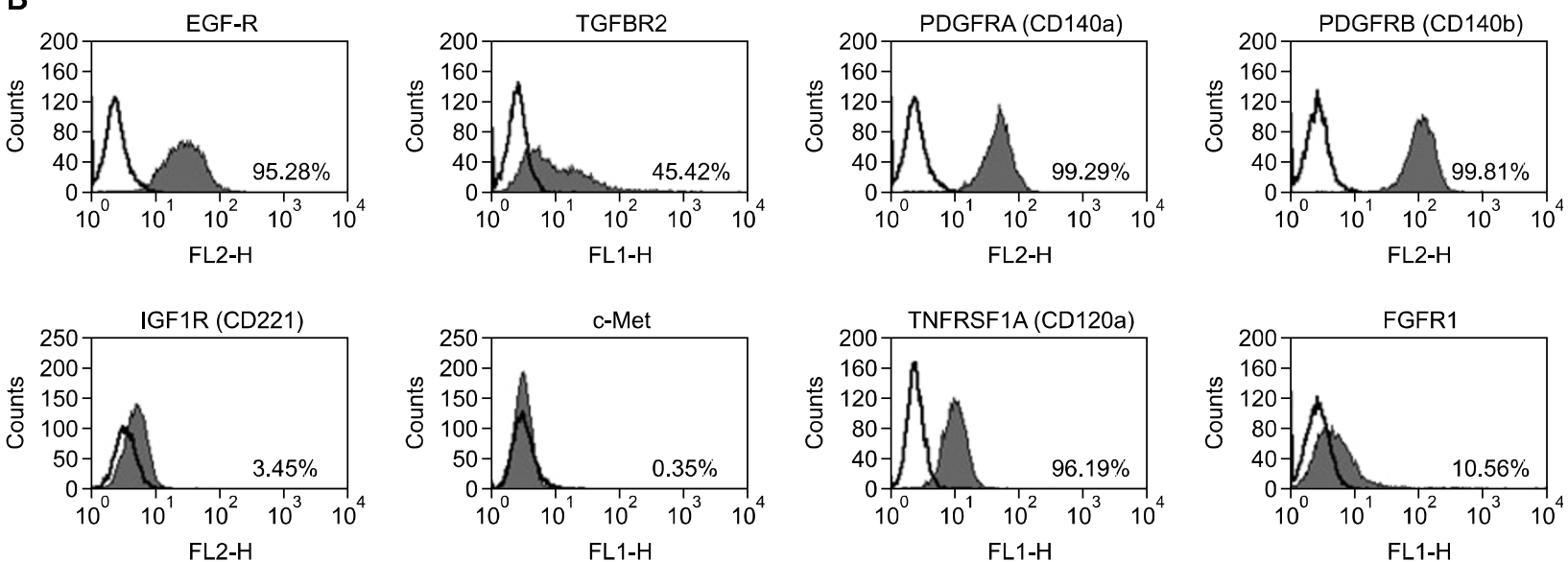

C

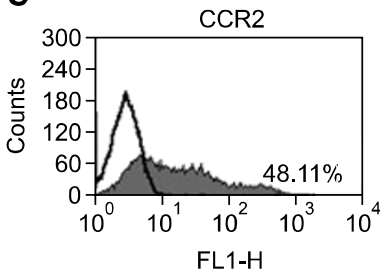

D
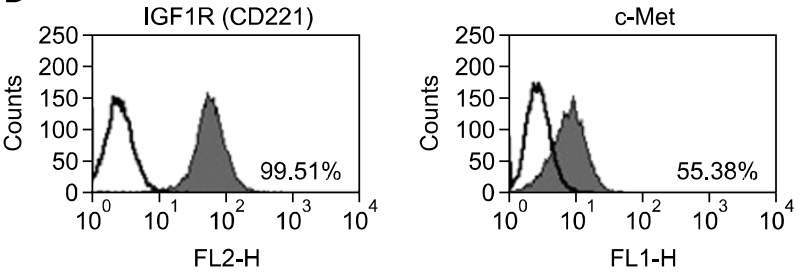

Figure 2. Representative expression of chemokine and growth factor (GF) receptors in human adipose tissue-derived mesenchymal stem cells (hAdMSCs) as assessed by flow cytometry. Histograms represent the surface expression of chemokine (A) and GF receptors (B). Expression of CCR2 is shown in PBMCs (C), and expression of IGF1R and c-Met is shown in A549 cells (D). The shaded regions indicate cells stained with anti-chemokine or anti-GF receptor antibodies, and the black line indicates the control (background) staining. The numbers in the histograms represent the percentage of cells that were positive for a given chemokine or GF receptor.

not reach the levels obtained with PDGF-AB, TGF- $\beta 1$ and TNF- $\alpha$. Among the chemokines, SDF- $1 \alpha$ ( 4.9-fold), B-cell attracting chemokine-1 (BCA-1)
( 4.8-fold), C-X-C motif chemokine 16 (CXCL16) $(\sim 4.5$-fold) and RANTES ( 3.3-fold) showed the best chemoattractant activity. The migration capacity of 
hAdMSCs in the presence of serum-free culture medium alone was low (negative control), although it increased in the presence of $30 \%$ FBS (positive control).

To evaluate whether the migration activity of hAdMSCs could be influenced by prior stimulation with chemokines or GFs, hAdMSCs were pretreated with RANTES, SDF-1 $\alpha$, hepatocyte growth factor (HGF), TNF- $\alpha$, PDGF-AB or TGF- $\beta 1$. As shown in Figure 1B, hAdMSCs pretreated with TNF- $\alpha$ showed the highest chemotaxis in response to $10 \% \mathrm{FBS}$; prestimulation with TNF- $\alpha$ increased cell migration about 5.37-fold when compared with unstimulated control cells. Human AdMSCs were therefore pretreated with TNF- $\alpha(100 \mathrm{ng} / \mathrm{ml})$ for $24 \mathrm{~h}$, and the migratory response to the chemokines and GFs was again investigated (Figure 1C). TNF- $\alpha$-primed hAdMSCs showed increased chemotaxis; compared with untreated hAdMSCs, pretreatment with TNF- $\alpha$ enhanced their migratory capacity by about 1.3-4.4-fold in response to the chemokines or GFs (Figure 1C). Furthermore, pretreatment with TNF- $\alpha$ increased the migration capacity of hAdMSCs by 13 -fold in response to $30 \%$ FBS compared to untreated hAdMSCs (data not shown).

\section{Human AdMSCs express chemokine and GF receptors}

The expression of receptors for chemokines and GFs in hAdMSCs was next investigated by flow cytometry and RT-PCR methods. As shown in Figure 2, flow cytometry analysis demonstrated

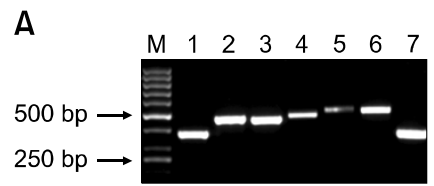

B

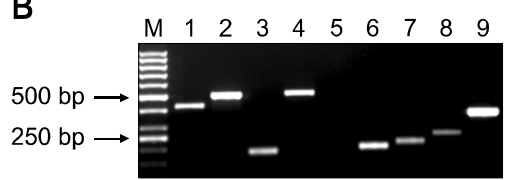

Figure 3. Transcription of chemokine and growth factor (GF) receptors in human adipose tissue-derived mesenchymal stem cells (hAdMSCs). Images show the expression of chemokine (A) and GF receptors mRNA (B) in hAdMSCs detected by RT-PCR. (A) M: marker, lane 1: CCR1 (380 bp), lane 2: CCR2 (474 bp), lane 3: CCR7 (461 bp), lane 4: CXCR4 (489 bp), lane 5: CXCR5 (494 bp), lane 6: CXCR6 (517 bp) and lane 7: GAPDH (362 bp). (B) M: marker, lane 1: EGF-R (419 bp), lane 2: TGFBR2 (498 bp), lane 3: PDGFRA (187 bp), lane 4: PDGFRB (508 bp), lane 5: IGF1R (299 bp), lane 6: c-Met (201 bp), lane 7: TNFRSF1A (218 bp), lane 8: FGFR1 (250 bp) and lane 9: GAPDH (362 bp). The products for the GAPDH housekeeping gene were used as positive controls. that hAdMSCs expressed C-C chemokine receptor type 1 (CCR1; receptor for RANTES), CCR7 [receptor for macrophage inflammatory protein (MIP)-3 3 , C-X-C chemokine receptor type 4 (CXCR4; receptor for SDF-1 $\alpha$ ), CXCR5 (receptor for BCA-1) and CXCR6 (receptor for CXCL16). The cells also expressed EGF-R, fibroblast growth factor (FGF) receptor 1 (FGFR1), TGF- $\beta$ receptor 2 (TGFBR2), TNF receptor superfamily, member $1 \mathrm{~A}$ (TNFRSF1A, CD120a), PDGF receptor A (PDGFRA, CD140a) and PDGF receptor $B$ (PDGFRB, CD140b). Human AdMSCs did not express CCR2, insulin-like growth factor (IGF) receptor 1 (IGF1R) or HGF receptor (HGFR, c-Met) at the protein level. However, the expression of CCR-2 in peripheral blood mononuclear cells (PBMCs), and the expression of IGF1R and c-Met in the human lung cancer cell line A549, were observed by flow cytometry, confirming the specificity of the antibodies (Figures 2C and 2D).

As shown in Figures $3 A$ and $3 B$, RT-PCR analysis demonstrated that hAdMSCs expressed CCR1, CCR2, CCR7, CXCR4, CXCR5 and CXCR6 chemokine receptors and EGF-R, FGFR1, TGFBR2, TNFRSF1A (CD120a), PDGFRA (CD140a), PDGFRB (CD140b) and c-Met GF receptors. The sequences of the products were confirmed by direct sequence analysis (data not shown). However, hAdMSCs did not express IGF1R (CD121) mRNA. The results of flow cytometry and RT-PCR analysis are summarized in Table 1.

Table 1. Protein and mRNA transcription of chemokine and growth factor receptors in human adipose tissue-derived mesenchymal stem cells

\begin{tabular}{lcc}
\hline $\begin{array}{c}\text { Cell surface receptor } \\
\text { (Chemokine) }\end{array}$ & $\begin{array}{c}\text { Expression } \\
\text { (Flow cytometry) }\end{array}$ & $\begin{array}{c}\text { Transcription } \\
\text { (RT-PCR) }\end{array}$ \\
\hline CCR1 (RANTES) & + & + \\
CCR2 (MCP-1) & - & + \\
CCR7 (MIP-3 $\beta$ ) & + & + \\
CXCR4 (SDF-1 $\alpha)$ & + & + \\
CXCR5 (BCA-1) & + & + \\
CXCR6 (CXCL16) & + & + \\
\hline Cell surface marker & Expression & Transcription \\
(Growth factor) & (Flow cytometry) & (RT-PCR) \\
\hline EGF-R (EGF) & + & + \\
FGFR1 (basic FGF) & + & + \\
TGFBR2 (TGF- $\beta 1)$ & + & + \\
PDGFRA (PDGF-A) & + & + \\
PDGFRB (PDGF-B) & + & + \\
IGF1R (IGF-1) & - & - \\
c-Met (HGF) & - & + \\
TNFRSF1A (TNF- $\alpha$ ) & + & + \\
\hline
\end{tabular}

+, detected; -, not detected. 


\section{Discussion}

The present study demonstrated for the first time that hAdMSCs can migrate in vitro in response to a large set of chemotactic factors, including chemokines and GFs. However, the chemotactic activity of chemokines toward hAdMSCs appeared to be less efficient than the chemotactic activity of GFs. The migratory activity of hAdMSCs was further enhanced by prestimulation with chemokines or GFs, especially TNF- $\alpha$. In addition, hAdMSCs expressed distinct sets of receptors for chemokines and GFs that are required for migration in response to these soluble factors.

Autologous and allogenic transplantation of AdMSCs has been shown to be effective in treating various diseases (Mizuno, 2010). There are various possible routes of administration of MSCs, including intravenous (Banas et al., 2008), intraarterial (Lu et al., 2001) or intracerebral (Chen et al., 2000) routes. Of these routes, intravenous administration is a convenient strategy if the cells are delivered to the injury site after systemic circulation through the lung. Recent demonstration of the in vivo homing properties of BMMSCs and AdMSCs has stimulated interest into intravenous applications of MSCs in cell therapy (Mosna et al., 2010). However, as noted above, the soluble factors inducing the migration of AdMSCs have not heretofore been reported. This study showed that PDGF-AB, TGF- $\beta 1$ and TNF- $\alpha$ had more chemoattractive activity toward these cells than the other soluble factors tested. In line with these results, PDGF was found to be a powerful chemotactic factor for MSCs, including osteoblasts from human and rat tissues (Fiedler et al., 2002). In addition, TGF- $\beta$ is known to be an important component of the overall process of wound healing, triggering a multitude of reactions needed for cell migration (Seomun et al., 2008).

Previous work demonstrated that BMMSCs that were pretreated with TNF- $\alpha$ exhibited enhanced migration capacity toward chemokines such as RANTES (Ponte et al., 2007). The enhancing effect of TNF- $\alpha$ pretreatment could potentially be mediated by modulating the expression of receptors for GFs and chemokines and/or ligand binding activity. In this regard, TNF- $\alpha$-stimulation of BMMSCs increased the expression of FGFR2, CCR2, CCR3 and CCR4 as well as the binding of RANTES to CCR3 (Ponte et al., 2007). Hence, TNF- $\alpha$ stimulation apparently increased the migration capability of BMMSCs toward RANTES by enhancing the expression of the CCR3 receptor and the interaction of RANTES with CCR3.

Based on these results (Ponte et al., 2007) and the similarities between AdMSCs and BMMSCs, the hypothesis was evaluated that pretreatment of hAdMSCs with a chemotactic factor or GF would similarly enhance their migration capability. Indeed, pretreatment of hAdMSCs with chemokines and GFs, especially TNF- $\alpha$, augmented their response to migratory signals. The mechanism of action of pretreatment of hAdMSCs with TNF- $\alpha$ is currently unknown, but it is also likely to be mediated by the enhanced expression of TNF- $\alpha$ receptors and/or increased receptor binding by TNF- $\alpha$. The TNF- $\alpha$ priming effect might also be mediated through the PI3K signaling pathway. In this regard, G-CSF signaling induces PI3K-mediated Akt phosphorylation, increasing membrane type 1-matrix metalloproteinase (MT1-MMP) expression. MT1-MMP-mediated CD44 proteolysis then results in human CD34+ progenitor cell egression and mobilization (Vagima et al., 2009). Further investigation will be necessary to understand the precise mechanism underlying the priming effect of TNF- $\alpha$ pretreatment on the migratory capability of hAdMSCs. However, taken together, the results of this study suggest that such pretreatment will increase the in vivo migratory capabilities of hAdMSCs. This would, in turn, allow them to move more readily into an injured region, thereby increasing their therapeutic potential in the clinical setting.

As hAdMSCs demonstrated a chemotactic response to chemokines and GFs, the expression of receptors for chemokines and GFs was next analyzed. The results demonstrated that hAdMSCs expressed chemokine CC (CCR1, CCR7) and CXC (CXCR4, CXCR5, CXCR6) and GF (EGF-R, FGFR1, TGFBR2, PDGFRA, PDGFRB, TNFRSF1A) receptors at the protein and mRNA level, as evidenced by flow cytometry and RT-PCR analysis. However, hAdMSCs did not express CCR2, IGF1R or c-Met at the protein level, although they did express mRNAs for CCR2 and c-Met, but not IFGR1. Therefore, it seems likely that CCR2 and c-Met mRNAs were transcribed but not translated into protein, whereas IGF1R was not expressed at all. On the other hand, both HGF and IGF-1 promoted the migration of hAdMSCs in vitro (Figure 1), although the hAdMSCs did not express the receptors for these chemokines at the protein level. It is possible that HGF or IGF-1 may bind nonspecifically to other receptors and thereby induce cellular migratory activity. The exact reason for this discrepancy is currently unknown and requires further study.

In conclusion, the present study demonstrates that the migration of hAdMSCs is regulated by GFs and chemokines, and can be enhanced by pretreatment with particular GFs and chemokines. 
This treatment strategy has great promise for in vivo applications to improve the delivery of hAdMSCs to cell-damaged injury sites, thereby increasing their treatment efficacy.

\section{Methods}

\section{Culture of human adipose tissue-derived mesenchymal stem cells}

Human adipose tissues were obtained by simple liposuction from abdominal subcutaneous fats with informed consent. Subcutaneous fats were digested with RTase (4 $\mathrm{ml}$ per $1 \mathrm{~g}$ fat; RNL BIO Co., Ltd., Seoul, Korea) for $60 \mathrm{~min}$ at $37^{\circ} \mathrm{C}$. The digested tissues were filtered through a 100 $\mu \mathrm{m}$ nylon sieve to remove cellular debris. Tissues were then centrifuged at $470 \mathrm{~g}$ for $5 \mathrm{~min}$ to obtain a pellet. The pellet was resuspended in RCME cell attachment medium (RNL BIO Co., Ltd.) and cultured overnight at $37^{\circ} \mathrm{C}$ in a humidified atmosphere containing $5 \% \mathrm{CO}_{2}$. After $24 \mathrm{~h}$, nonadherent cells were removed and washed with PBS. The cell medium was changed to RKCM cell growth medium (RNL BIO Co., Ltd.) containing 5\% FBS (Invitrogen, Carlsbad, CA). The cells were maintained for 4 days until confluent (passage zero). When the cells reached $90 \%$ confluency, they were subcultured and expanded in RKCM for two or three passages. They were then used for experiments. The stem cell potency of the cultured hAdMSCs was confirmed by their expression of MSC specific proteins and their differentiation potency (data not shown).

\section{Culture of human lung cancer cells}

The human lung cancer cell line A549 was purchased from the Korean Cell Line Bank (Seoul, Korea). The cells were cultured in RPMI-1640 medium (Invitrogen) supplemented with $10 \%$ FBS. Cultures were maintained at $37^{\circ} \mathrm{C}$ in a humidified atmosphere containing $5 \% \mathrm{CO}_{2}$.

\section{Cell migration assay}

The migration assay was performed using a Transwell twochamber cell culture method and Transwell inserts (3422; Corning, Cambridge, MA) with an $8 \mu \mathrm{m}$ pore polycarbonate membrane. The uppermost side of the Transwell membrane was coated with $0.1 \%$ gelatin in PBS (Sigma-Aldrich, St. Louis, MO) for $2 \mathrm{~h}$ at $37^{\circ} \mathrm{C}$. In Experiment 1 , unstimulated hAdMSCs were seeded at a density of $2.0 \times$ $10^{4}$ cells $/ 200 \mu \mathrm{l}$ in the upper chamber of the Transwell apparatus and incubated for $2 \mathrm{~h}$ at $37^{\circ} \mathrm{C}$ in a humidified atmosphere containing $5 \% \mathrm{CO}_{2}$. Cells were allowed to migrate toward medium $(500 \mu \mathrm{l})$ in the lower chamber containing chemokines or GFs (100 ng/ml). In Experiment 2, hAdMSCs were prestimulated with RANTES, SDF-1 $\alpha$, HGF, TNF- $\alpha$, PDGF-AB or TGF- $\beta 1(100 \mathrm{ng} / \mathrm{ml}$ for $24 \mathrm{~h})$ and were seeded at a density of $2.0 \times 10^{4}$ cells $/ 200 \mu$ in the upper chamber of the Transwell apparatus and incubated for $2 \mathrm{~h}$ at $37^{\circ} \mathrm{C}$ in a humidified atmosphere containing $5 \% \mathrm{CO}_{2}$. Cells were allowed to migrate toward me- dium $(500 \mu \mathrm{l})$ in the lower chamber containing 10\% FBS. In Experiment 3 , cells were pretreated with TNF- $\alpha(100 \mathrm{ng} / \mathrm{ml}$ for $24 \mathrm{~h})$ and were seeded at a density of $2.0 \times 10^{4}$ cells/200 $\mu$ in the upper chamber of the Transwell apparatus and incubated for $2 \mathrm{~h}$ at $37^{\circ} \mathrm{C}$ in a humidified atmosphere containing $5 \% \mathrm{CO}_{2}$. Cells were allowed to migrate toward medium $(500 \mu \mathrm{l})$ in the lower chamber containing each chemokine or GF (100 ng/ml). The chemokines and GFs employed were RANTES, MCP-1, MIP-3 $\beta$, SDF- $1 \alpha$, BCA-1, CXCL16, EGF, basic FGF (bFGF), HGF, TGF- $\beta 1$, IGF-1, PDGF-AB and TNF- $\alpha$. Each factor was obtained from PeproTech (Rocky Hill, NJ). Migration observed in serum-free and $30 \%$ FBS-containing media were employed as the negative and positive control, respectively. After 24 $\mathrm{h}$ of incubation at $37^{\circ} \mathrm{C}$ in a humidified atmosphere containing $5 \% \mathrm{CO}_{2}$, non-migratory cells were carefully removed from upper face of the Transwell insert with a cotton swab. The attached cells remaining on the Transwell insert were fixed with $70 \%$ methanol and stained with $0.5 \%$ crystal violet in $20 \%$ methanol for $1 \mathrm{~h}$. After washing, the stained cells that had migrated from the upper to the lower side of the membrane were counted under an inverted bright-field microscope at $\times 100$ magnification. The number of migrated cells was expressed as the percent change from the control value. Each experiment was performed in triplicate.

\section{Flow cytometry analysis}

Human AdMSCs were detached from flasks by trypsinization, washed twice in PBS and resuspended in PBS (100 $\mu \mathrm{l})$ containing 10\% FBS. Cells were incubated for $2 \mathrm{~h}$ at $4^{\circ} \mathrm{C}$ with the following FITC- or phycoerythrin-conjugated antibodies to chemokine or GF receptors: anti-human CCR1 (MAB145), anti-human CCR2 (MAB150), anti-human CCR7 (MAB197), anti-human CXCR4 (MAB170), anti-human CXCR5 (MAB190), anti-human CXCR6 (MAB699) or anti-human HGFR/c-Met (FAB3582F) (all from R\&D Systems, Minneapolis, MN); anti-human EGF-R (555997), anti-human PDGFRA (556002), anti-human PDGFRB (558821), anti-human TNFRSF1A (550514) or anti-human IGF1R (555999) (all from BD Pharmingen, San Diego, CA); anti-TGFBR2 (SC-17799) (from Santa Cruz Biotechnology, Santa Cruz, CA); or anti-human FGFR1 (ab823) (from Abcam, Boston, MA). Dilution of the antibodies was 1:100. As a negative control, the staining procedure was performed in the absence of the primary antibody. Human PBMCs were used as positive control for the anti-CCR2 antibody (Reale et al., 2008), and A549 cells were used as positive control for the anti-IGF1R and c-Met antibodies (To et al., 2002; Kong et al., 2008). Data were acquired using a BD FACS Calibur flow cytometry system (BD Biosciences) and are presented as the percentage of cells expressing each protein.

\section{RNA extraction and RT-PCR}

Total RNAs were extracted using an Easy-spin ${ }^{T M}$ Total RNA Extraction Kit (iNtRON Co., Seongnam, Korea). The cDNAs were synthesized from $2 \mu \mathrm{g}$ of total RNA using RevoScript ${ }^{T M}$ RT PreMix (iNtRON). Reverse transcription (RT) was performed for $60 \mathrm{~min}$ at $50^{\circ} \mathrm{C}$, and reverse transcriptase inactivation was performed for $5 \mathrm{~min}$ at $95^{\circ} \mathrm{C}$. 
The cDNAs were subjected to PCR amplification with primers as described in the Supplemental Data Table S1. The $\mathrm{RT}$ reaction mixture $(2 \mu \mathrm{l})$ was added to a PCR mix containing $1.5 \mathrm{mM} \mathrm{MgCl}_{2}, 0.2 \mathrm{mM}$ dNTP, $0.4 \mathrm{pM}$ of each primer and $0.5 \mathrm{U}$ h-Taq DNA polymerase (SolGent, Seoul, Korea) in a total volume of $20 \mu \mathrm{l}$. The PCR reactions were performed for 40 cycles. Each cycle consisted of an initial denaturation at $95^{\circ} \mathrm{C}$ for $15 \mathrm{~min}$, followed by $95^{\circ} \mathrm{C}$ for $20 \mathrm{~s}$, an annealing reaction at a specified annealing temperature (Supplemental Data Table S1) for $40 \mathrm{~s}$, followed by $72^{\circ} \mathrm{C}$ for $1 \mathrm{~min}$. The reaction was terminated by a final extension at $72^{\circ} \mathrm{C}$ for $5 \mathrm{~min}$. GAPDH was used as a positive control. The PCR products were resolved by electrophoresis on $2 \%$ agarose gels and visualized by ethidium bromide staining using a LAS-3000 imaging system (Fujifilm Europe, Sint Niklaas, Belgium). The experiments were repeated three times with independent samples.

\section{Statistical analysis}

Data are representative of three individual experiments with triplicate samples and are presented as mean values \pm SD. The data were analyzed using the multivariate ANOVA (SPSS Ver. 17.0) followed by Tukey's t-test. $P$-values of less than 0.05 were considered statistically significant.

\section{Supplemental data}

Supplemental Data include a table and can be found with this article online at http://e-emm.or.kr/article/article_files/ SP-43-10-07.pdf.

\section{Acknowledgements}

This work was funded and supported by the Stem Cell Research Center of RNL BIO Co., Ltd. (Korea).

\section{References}

Bacou F, el Andalousi RB, Daussin PA, Micallef JP, Levin JM, Chammas M, Casteilla L, Reyne Y, Nougues J. Transplantation of adipose tissue-derived stromal cells increases mass and functional capacity of damaged skeletal muscle. Cell Transplant 2004;13:103-11

Banas A, Teratani T, Yamamoto Y, Tokuhara M, Takeshita F, Osaki M, Kawamata M, Kato T, Okochi H, Ochiya T. IFATS collection: in vivo therapeutic potential of human adipose tissue mesenchymal stem cells after transplantation into mice with liver injury. Stem Cells 2008;26:2705-12

Cai L, Johnstone BH, Cook TG, Tan J, Fishbein MC, Chen PS, March KL. IFATS collection: Human adipose tissue-derived stem cells induce angiogenesis and nerve sprouting following myocardial infarction, in conjunction with potent preservation of cardiac function. Stem Cells 2009;27: 230-7

Chen J, Li Y, Chopp M. Intracerebral transplantation of bone marrow with BDNF after MCAo in rat. Neuropharmacology 2000;39:711-6
Cho KS, Park HK, Park HY, Jung JS, Jeon SG, Kim YK, Roh HJ. IFATS collection: Immunomodulatory effects of adipose tissue-derived stem cells in an allergic rhinitis mouse model. Stem Cells 2009;27:259-65

Erices A, Conget $\mathrm{P}$, Minguell JJ. Mesenchymal progenitor cells in human umbilical cord blood. $\mathrm{Br} \mathrm{J}$ Haematol 2000; 109:235-42

Fiedler J, Roderer G, Gunther KP, Brenner RE. BMP-2, BMP-4, and PDGF-bb stimulate chemotactic migration of primary human mesenchymal progenitor cells. J Cell Biochem 2002;87:305-12

in 't Anker PS, Scherjon SA, Kleijburg-van der Keur C, de Groot-Swings GMJS, Claas FHJ, Fibbe WE, Kanhai HHH. Isolation of mesenchymal stem cells of fetal or maternal origin from human placenta. Stem Cells 2004;22:1338-45

Kong MJ, Dong AQ, Wu W, Ma ZY, Cheng HF, Qian JF, Fan JQ. [Biological behaviors and chemosensitivity of NSCLC A549 cells after IGF-IR gene silencing by targeting RNAi in vitro]. Zhejiang Da Xue Xue Bao Yi Xue Ban 2008;37:373-80

Lu D, Li Y, Wang L, Chen J, Mahmood A, Chopp M. Intraarterial administration of marrow stromal cells in a rat model of traumatic brain injury. J Neurotrauma 2001;18: 813-9

Mizuno $H$. Adipose-derived stem and stromal cells for cell-based therapy: current status of preclinical studies and clinical trials. Curr Opin Mol Ther 2010;12:442-9

Mosna F, Sensebe L, Krampera M. Human bone marrow and adipose tissue mesenchymal stem cells: a user's guide. Stem Cells Dev 2010;19:1449-70

Mouiseddine M, Francois S, Semont A, Sache A, Allenet B, Mathieu N, Frick J, Thierry D, Chapel A. Human mesenchymal stem cells home specifically to radiation-injured tissues in a non-obese diabetes/severe combined immunodeficiency mouse model. Br J Radiol 2007;80 Spec No 1:S49-55

Pittenger MF, Mackay AM, Beck SC, Jaiswal RK, Douglas R, Mosca JD, Moorman MA, Simonetti DW, Craig S, Marshak DR. Multilineage potential of adult human mesenchymal stem cells. Science 1999;284:143-7

Ponte AL, Marais E, Gallay N, Langonne A, Delorme B, Herault $\mathrm{O}$, Charbord $\mathrm{P}$, Domenech J. The in vitro migration capacity of human bone marrow mesenchymal stem cells: comparison of chemokine and growth factor chemotactic activities. Stem Cells 2007;25:1737-45

Reale M, larlori C, Feliciani C, Gambi D. Peripheral chemokine receptors, their ligands, cytokines and Alzheimer's disease. J Alzheimers Dis 2008;14:147-59

Saito T, Kuang JQ, Bittira B, Al-Khaldi A, Chiu RC. Xenotransplant cardiac chimera: immune tolerance of adult stem cells. Ann Thorac Surg 2002;74:19-24; discussion

Sen A, Lea-Currie YR, Sujkowska D, Franklin DM, Wilkison WO, Halvorsen YD, Gimble JM. Adipogenic potential of human adipose derived stromal cells from multiple donors is heterogeneous. J Cell Biochem 2001;81:312-9

Seomun Y, Kim JT, Joo CK. MMP-14 mediated MMP-9 expression is involved in TGF-beta1-induced keratinocyte migration. J Cell Biochem 2008;104:934-41 
Sordi V, Malosio ML, Marchesi F, Mercalli A, Melzi R, Giordano T, Belmonte N, Ferrari G, Leone BE, Bertuzzi F, Zerbini G, Allavena P, Bonifacio E, Piemonti L. Bone marrow mesenchymal stem cells express a restricted set of functionally active chemokine receptors capable of promoting migration to pancreatic islets. Blood 2005;106:419-27

To Y, Dohi M, Matsumoto K, Tanaka R, Sato A, Nakagome K, Nakamura T, Yamamoto K. A two-way interaction between hepatocyte growth factor and interleukin- 6 in tissue invasion of lung cancer cell line. Am J Respir Cell Mol Biol 2002; 27:220-6

Vagima $Y$, Avigdor A, Goichberg P, Shivtiel S, Tesio M, Kalinkovich A, Golan K, Dar A, Kollet O, Petit I, Perl O,
Rosenthal E, Resnick I, Hardan I, Gellman YN, Naor D, Nagler A, Lapidot T. MT1-MMP and RECK are involved in human CD34+ progenitor cell retention, egress, and mobilization. J Clin Invest 2009;119:492-503

Wei X, Du Z, Zhao L, Feng D, Wei G, He Y, Tan J, Lee WH, Hampel H, Dodel R, Johnstone BH, March KL, Farlow MR, Du Y. IFATS collection: The conditioned media of adipose stromal cells protect against hypoxia-ischemia-induced brain damage in neonatal rats. Stem Cells 2009;27:478-88

Zuk PA, Zhu M, Mizuno H, Huang J, Futrell JW, Katz AJ, Benhaim P, Lorenz HP, Hedrick MH. Multilineage cells from human adipose tissue: implications for cell-based therapies. Tissue Eng 2001;7:211-28 